\title{
Management of acute asthma in adults in the emergency department: nonventilatory management
}

\author{
Rick Hodder MD MSc, M. Diane Lougheed MD MSc, Brian H. Rowe MD MSc, \\ J. Mark FitzGerald MD, Alan G. Kaplan MD, R. Andrew Mclvor MD MSc
}

\section{The case}

Peter, a 26-year-old man with chronic, poorly controlled asthma, presents to a walk-in clinic reporting increasing asthma symptoms over a period of one week. He has been needing up to 20 puffs of salbutamol per day. An acute exacerbation of asthma is diagnosed, and the patient is immediately referred to the emergency department.

A cute asthma is a common medical emergency, which, despite repeated review ${ }^{1-6}$ and the publication of international ${ }^{7}$ and national ${ }^{8}$ guidelines, including the Canadian Asthma Consensus Guidelines, ${ }^{9-11}$ often remains poorly managed. ${ }^{12-20}$ Although there are some signs that evidence-based management of this disorder is improving, ${ }^{17,21-23}$ a recent survey of the management of asthma in children and adults in the emergency department revealed wide variations in care and substantial gaps in management in certain key areas. ${ }^{19}$ These included poor adherence to published guidelines on the management of asthma, infrequent measurement of peak expiratory flow, infrequent use of systemic corticosteroids and poor rates of referral to asthma educational services.

Exacerbations of asthma account for about $25 \%$ of the total costs of asthma care in Canada. ${ }^{24}$ Most exacerbations treated in the emergency department resolve within two hours after presentation. Only about $6 \%-13 \%$ of affected patients require admission to hospital, ${ }^{17,25}$ and far fewer require admission to a critical care unit.

The most common triggers of exacerbations are viral infections and environmental allergens. Exposures in the workplace (to allergens, sensitizers or irritants) can also trigger exacerbations. ${ }^{26}$ The onset and duration of symptoms and the worsening of airflow obstruction before presentation are variable, but these problems usually occur over several hours. ${ }^{2,27}$ Even in fatal or near-fatal attacks, this means there is potential for early recognition and aggressive treatment. Rarely, a patient has rapid, catastrophic onset of acute asthma, which can be fatal. Whether this reflects a separate phenotype of asthma is unclear. ${ }^{2,6,28-33}$

Although the prevalence of asthma is increasing, the overall rate of death from asthma has been falling in Canada, from 400-500 deaths in $1995^{34}$ to 268 deaths in 2004. ${ }^{35}$ Asthma

\section{Key points}

- A patient with a history of severe asthma exacerbations is at risk for potentially fatal asthma and will need close monitoring and aggressive therapy.

- Continuous monitoring of oxyhemoglobin saturation and objective measurement of airflow obstruction (by spirometry) or peak expiratory flow are necessary for optimal management of acute exacerbations of asthma.

- Bronchodilators should be administered by inhalation, with administration by nebulizer and by pressurized metered-dose inhaler (preferably with a valved holding chamber) being equally effective.

- Combined use of high-dose inhaled corticosteroids and oral corticosteroids at the time of discharge from the emergency department is recommended to reduce the risk of relapse of the asthma exacerbation.

- Upon discharge from the emergency department or the hospital, every patient should have a written management (action) plan detailing how to prevent and manage future exacerbations.

mortality rates increase with age. ${ }^{35}$ Overall mortality from acute exacerbations is low $(<0.1 \%)$, and most deaths related to asthma occur before arrival at a hospital. There are many risk factors for death or near death from acute asthma (Table 1), but a key contributor is failure of patients or physicians to appreciate the severity of the exacerbation, which leads to delayed and insufficiently aggressive treatment. ${ }^{40,47,75-}$ ${ }^{77}$ Of note, both heightened and blunted perception of asthma symptoms have been implicated in excess morbidity and mortality related to asthma..$^{27,51,62,64,78-81}$ Patients with blunted perception of their symptoms do not recognize that an exacerbation is occurring and therefore permit the exacerbation to progress before seeking help. Patients with heightened sensi-

From the Divisions of Pulmonary and Critical Care Medicine (Hodder), University of Ottawa, Ottawa, Ont.; the Division of Respirology, Department of Medicine (Lougheed), Queen's University, Kingston, Ont.; the Department of Emergency Medicine and School of Public Health (Rowe), University of Alberta, Edmonton, Alta.; the Division of Respiratory Medicine (FitzGerald), University of British Columbia, Vancouver, BC; the Department of Family and Community Medicine (Kaplan), University of Toronto, Toronto, Ont.; the Firestone Institute for Respiratory Health (Mclvor), St. Joseph's Healthcare, Hamilton, Ont.; and the Department of Medicine (Mclvor), McMaster University, Hamilton, Ont.

CMAJ 2009. DOI:10.1503/cmaj.080072 
Table 1: Risk factors for potentially fatal asthma

\begin{tabular}{|c|c|}
\hline Risk factor & $\begin{array}{l}\text { Level of } \\
\text { evidence }\end{array}$ \\
\hline \multicolumn{2}{|l|}{ Control and severity of asthma } \\
\hline Poor control of asthma $a^{27,36-43}$ & II-2 \\
\hline History of admission to hospital for asthma ${ }^{38,39,41,42,44,45}$ & $\mathrm{II}-2$ \\
\hline $\begin{array}{l}\text { Previous admission to an intensive care unit for } \\
\text { asthma } \text { 27,38,42 }^{2}\end{array}$ & II-2 \\
\hline $\begin{array}{l}\text { Previous need for mechanical ventilation for } \\
\text { asthma }\end{array}$ & II-2 \\
\hline $\begin{array}{l}\text { History of multiple visits to the emergency } \\
\text { department for asthma }\end{array}$ & II-2 \\
\hline $\begin{array}{l}\text { Failure to consult family physician for worsening } \\
\text { asthma }{ }^{27,29,40,42,47}\end{array}$ & II-2 \\
\hline Pattern of sudden attacks $\mathrm{s}^{29,30,48}$ & II-2 \\
\hline History of previous hypercapnic asthma attack ${ }^{2,49,50}$ & II-2 \\
\hline \multicolumn{2}{|l|}{ Use of medications } \\
\hline Poor adherence with medications for asthma $a^{31,36,39,40,42}$ & II-2 \\
\hline $\begin{array}{l}\text { Excessive or increasing reliance on short-acting } \\
\beta_{2} \text {-adrenergic bronchodilators }{ }^{38,51-53}\end{array}$ & II-2 \\
\hline Underuse of inhaled corticosteroids ${ }^{27,31,54}$ & $\mathrm{II}-2$ \\
\hline History of need for oral corticosteroids ${ }^{27,31,38,41,44,45}$ & II-2 \\
\hline $\begin{array}{l}\text { Monotherapy with a long-acting } \beta_{2} \text {-adrenergic } \\
\text { bronchodilator }{ }^{55-58}\end{array}$ & 1 \\
\hline $\begin{array}{l}\text { Prescription of multiple types of asthma } \\
\text { medications }{ }^{44}\end{array}$ & II-2 \\
\hline Increased use of oral theophylline ${ }^{27,38,42}$ & II-2 \\
\hline $\begin{array}{l}\text { Asthma that is worsened by acetylsalicylic acid or } \\
\text { nonsteroidal anti-inflammatory drugs }{ }^{59-61}\end{array}$ & II-3 \\
\hline \multicolumn{2}{|l|}{ Psychosocial profile } \\
\hline Older age $\mathrm{e}^{27,42}$ & II-2 \\
\hline Poor perception of breathlessness ${ }^{27,36,62-64}$ & II-2 \\
\hline $\begin{array}{l}\text { Psychological dysfunction (psychosis, anxiety, } \\
\text { depression, denial) }\end{array}$ & II-2 \\
\hline $\begin{array}{l}\text { Socio-economic factors (family discord, low } \\
\text { income, ethnicity) }\end{array}$ & II-2 \\
\hline Continued smoking ${ }^{38,72,73}$ & II-2 \\
\hline Failure to use a written asthma action plan ${ }^{73}$ & II-2 \\
\hline Poor understanding of asthma and its treatment & III \\
\hline Frequent missed appointments & III \\
\hline Substantial lifestyle alterations because of asthma & III \\
\hline Self-discharge from hospital & III \\
\hline Learning difficulties & III \\
\hline Abuse of alcohol or drugs $s^{73,74}$ & II-3 \\
\hline \multicolumn{2}{|l|}{ Physician-related factors } \\
\hline $\begin{array}{l}\text { Failure to initiate (or delay in initiating) } \\
\text { appropriately aggressive therapy }{ }^{40,47,75,76}\end{array}$ & II-2 \\
\hline $\begin{array}{l}\text { Failure to initiate mechanical ventilation when } \\
\text { appropriate }^{47}\end{array}$ & II-2 \\
\hline $\begin{array}{l}\text { Failure to objectively evaluate the severity of } \\
\text { airflow obstruction }{ }^{47}\end{array}$ & II-3 \\
\hline $\begin{array}{l}\text { Failure to recommend appropriate strategies } \\
\text { for avoidance of allergens, irritants and } \\
\text { workplace-related factors }\end{array}$ & III \\
\hline
\end{tabular}

tivity to symptoms may exhibit overreliance on short-acting $\beta_{2}$-adrenergic bronchodilators, which can also result in delays in seeking definitive treatment.

Effective and efficient treatment of acute asthma in the emergency department requires prompt recognition of the signs and symptoms that indicate a potentially fatal asthma attack (Table 2). Appropriate management of patients whose distress persists despite aggressive initial therapy also requires an awareness of conditions that may mimic an acute attack of asthma (Box 1).

Once the acute exacerbation has been managed, most patients will be well enough for discharge from the emergency department. In both Canada and the United States, however, relapse rates remain unacceptably high, ranging from $12 \%$ to $16 \%$ within two weeks after treatment in the emergency department in one recent study. ${ }^{17}$ To reduce the risk of relapse, optimizing management after discharge should be a high priority, but observations suggest that discharge planning in this setting is poor. ${ }^{23}$ This may reflect an underappreciation of the important role of patient education in the emergency department. ${ }^{20,23,88-90}$ Most patients, but especially those with frequent or severe exacerbations and those who meet other high-risk criteria (Table 1), will benefit from formal referral to an asthma specialist or an asthma educator. ${ }^{91,92}$

\section{Sources of information}

In this article, we present the Canadian Thoracic Society's updated evidence-based key messages for the nonventilatory

Table 2: Signs and symptoms that may suggest a potentially fatal asthma attack

\begin{tabular}{lr}
\hline Sign or symptom & $\begin{array}{r}\text { Level of } \\
\text { evidence }\end{array}$ \\
\hline
\end{tabular}

\section{Signs}

Use of accessory muscles III

Heart rate $>120 /$ min or increasing ${ }^{2,6} \quad$ II-2

Respiratory rate $>25-30 / \mathrm{min}$ III

Difficulty speaking because of dyspnea or fatigue III

Altered level of consciousness III

Quiet chest in a patient who has dyspnea or III reduced level of consciousness

Diaphoresis $^{82} \quad$ II-2

Inability to lie in the supine position because II-2 of breathing distress ${ }^{82}$

Peak expiratory flow $<30 \%$ of predicted or IIforced expiratory volume in 1 second $<25 \%$ of predicted $1-2 \mathrm{~h}$ after initial therapy ${ }^{83,84}$

Oxygen saturation $<90 \%$

Cyanosis III

\section{Symptoms}

Sense of progressive breathlessness or air hunger III

Sense of fear or impending doom III

Progressive agitation or anxiety III 
management of acute asthma. A separate article in this series addresses assisted ventilation for acute asthma. ${ }^{93}$ In collating evidence for this update, we did not undertake a formal metaanalysis. Instead, we used the comprehensive PubMed search that was used by the Global Initiative for Asthma group, ${ }^{7}$ extending it to August 2009. This search strategy used the following criteria: "asthma," "adults," "all fields," "only items with abstracts," "clinical trial," "human" and "all dates." We included the following additional criteria: "status asthmaticus," "near fatal asthma," "acute disease" and "all languages." We used the same terms to search the database of the Cochrane Airways Group. We also searched for review articles in the Evidence-Based Medicine Reviews from the Cochrane (CENTRAL), MEDLINE, CINAHL and EMBASE databases using the search criteria "acute severe asthma," "life-threatening asthma" and "status asthmaticus." We searched the bibliographies of all identified reviews for additional relevant publications. We also reviewed three recent evidence-based guidelines (the Global Initiative for Asthma, ${ }^{7}$ the British Guideline on the Management of Asthma ${ }^{8}$ and the report of a joint task force of the American Academy of Asthma, Allergy and Immunology, the American Academy of Emergency Medicine and the American Thoracic Society ${ }^{94}$ ) and their respective bibliographies. At least two members of the Canadian Thoracic Society Asthma Committee who were also authors of the current report verified relevant references and assigned the recommendation grades and levels of evidence.

We based our grades of evidence on those of the Canadian Task Force on Preventive Health Care, ${ }^{95}$ as detailed in a previous article in this series. ${ }^{96}$ Because of the difficulty of conducting randomized controlled trials of potentially fatal asthma, some of the key messages presented later in this article represent only grade I recommendations based on level II-3 or level III evidence.

\section{Overview of managing acute asthma in the emergency department}

Optimum management of acute asthma in the emergency department requires rapid access to facilities and personnel capable of delivering bronchodilators appropriately, obtaining objective assessment of the severity of the episode (by measurement of lung function), appropriately monitoring oxygen delivery and ensuring safe disposition and referral of patients with asthma.

The general approach to caring for a patient with acute asthma in the emergency department starts with an initial quick assessment to determine whether the patient has any of the risk factors for (Table 1) or signs or symptoms of (Table 2) potentially fatal asthma. Patients meeting these criteria should be immediately triaged to a closely monitored setting within the emergency department for at least one to two hours after arrival. Because acute asthma is an inherently unstable and unpredictable condition, an intravenous line should be inserted and oxygenation continuously assessed and recorded by pulse oximetry. It is important to obtain objective measurements of lung function in this set-

\section{Box 1: Conditions that may mimic acute asthma}

- Upper airway obstruction

- Foreign-body aspiration

- Vocal cord dysfunction syndrome $e^{85-87}$

- Pulmonary edema

- Acute exacerbation of chronic obstructive pulmonary disease

- Hysterical conversion reaction

- Munchausen syndrome

ting; therefore, all patients should undergo either baseline spirometry (to determine forced expiratory volume in $1 \mathrm{sec}-$ ond $\left.\left[\mathrm{FEV}_{1}\right]\right)$ or measurement of peak expiratory flow rate, and these measurements should be repeated every 30-60 minutes to help guide therapy. Following the principles of concurrent management, ${ }^{97}$ treatment with supplemental oxygen and inhaled $\beta_{2}$-adrenergic bronchodilators should begin simultaneously with the initial assessment, and consideration should also be given to administering an oral or intravenous dose of corticosteroids immediately. Subsequent care will be determined in part by the response to initial therapy and should follow the recommendations outlined below. All health care professionals treating patients in the emergency setting should be skilled in crisis resource management, which involves good communication, delegation of tasks and frequent re-evaluation and reassessment of the patient. ${ }^{97}$

Most of the recommendations for treating acute asthma that appeared in the 1996 guidelines of the Canadian Association of Emergency Physicians and the Canadian Thoracic Society ${ }^{9}$ and in the 1999 Canadian Asthma Consensus Guidelines ${ }^{10,11}$ remain unchanged. Here, we summarize new evidence on the potential role of inhaled corticosteroids in the management of acute asthma. The recommendations presented here either extend or do not differ substantially from other recently published national ${ }^{8,9}$ and international ${ }^{7}$ guidelines for the management of acute asthma.

Although initial attention should focus on acute treatment, management of acute asthma begins with assessing the severity of the attack and determining whether the patient is at risk of potentially fatal asthma.

\section{The case continued}

The patient is immediately started on supplemental oxygen $40 \%$ by mask and is given inhaled bronchodilators. Fifteen minutes later, he is breathing somewhat more easily and is able to provide additional history. He reports that as a child he had numerous allergies. Now, he is living in a mouldy basement apartment with a roommate who owns a cat. Although he has prescriptions for salmeterol and fluticasone combined in a single inhaler, he is unemployed and unable to afford this medication. The last time he took inhaled corticosteroids was three weeks ago, when he finished a physician's sample of budesonide. Since then, he has been relying on salbutamol, which he has been getting from several walk-in clinics. In addition, he has received two short courses of oral corticosteroids in the past three months. 


\section{Assessment and monitoring}

Meta-analyses and systematic reviews ${ }^{27,7,38,55,56,58,7,9,98,99}$ and casecontrol $^{27,29,36,39,42,46,51,54,64,65,73}$ and observational ${ }^{37,40,66,68,100}$ studies have identified clinical and historical features that can be used to identify patients at high risk for fatal or near-fatal asthma (Table 1). An evaluation for these risk factors is important because when stable, patients who have survived a near-fatal episode of asthma are indistinguishable from other patients with asthma, at least on clinical grounds. ${ }^{31}$ The strongest predictor of potentially fatal asthma is a history of previous admission to hospital or intensive care for asthma. ${ }^{6,27,38}$ Patients with such a history should be identified and monitored closely during the first one to two hours after arrival in the emergency department, regardless of apparent stability or improvement in response to initial therapy. Prior history of unstable or poorly controlled asthma or recent need for aggressive management (e.g., systemic corticosteroids) should also alert the treating health care professional to the possibility that the patient's asthma could be resistant to firstline treatment and therefore might escalate in severity and become life-threatening. Obtaining a thorough history of the patient's use of prescription and nonprescription medications and recent adherence with therapy is important, because this will affect planned initial and long-term management. Psychosocial factors may be associated with poorly controlled and potentially fatal asthma. ${ }^{36,37,46,68,69}$ Patients with a poor perception of dyspnea have been identified in some ${ }^{62,64,79}$ but not all ${ }^{27,36,63}$ studies of risk factors for potentially fatal asthma, but there is no simple, validated way to test for this factor in a primary care setting. ${ }^{101}$ Failure of the treating physician to appreciate the severity of the acute asthma attack and to initiate appropriately aggressive therapy has also been shown to be a risk factor for a fatal outcome. ${ }^{40,47,75-77}$

There is some consensus about the signs and symptoms that may assist in the recognition of a potentially fatal exacerbation of asthma (Table 2)., ${ }^{2,5-7,82-84,102,103}$ For example, diaphoresis and an inability to lie in the supine position have been correlated with severe airflow obstruction as measured by peak expiratory flow rate. Increasing heart rate is closely correlated with increasing severity of asthma, ${ }^{104}$ and it is incorrect to assume that tachycardia is caused by use of a $\beta_{2^{-}}$ adrenergic bronchodilator. ${ }^{1}$ There is little correlation among the signs listed in Table 2, which develop independently, and their presence is not generally predictive of adverse outcomes. ${ }^{2,13,102,103,105}$

The absence of these symptoms and signs does not guarantee that the exacerbation is unimportant, as patients who appear well may have severe airflow obstruction. ${ }^{2}$ Although pulsus paradoxus may correlate with the degree of obstruction, ${ }^{106}$ it can diminish as the patient becomes fatigued and loses the ability to generate strong inspiratory efforts. Absence of pulsus paradoxus may therefore be wrongly interpreted as a sign of improvement. Measuring pulsus paradoxus in acute exacerbations is difficult and of limited prognostic use. ${ }^{107}$ Similarly, the nature of wheeze has limited correlation with objective measures of airway obstruction and is a poor predictor of the need for admission to hospital..$^{2,5,108}$ However, the absence of wheeze in a patient with dyspnea or altered level of consciousness is an ominous sign..$^{50}$ Wheeze may return as airflow improves in response to therapy. The physical examination should also include assessment for stridor, which could indicate obstruction of the upper airway mimicking asthma. Asymmetric breath sounds and subcutaneous emphysema may indicate the presence of barotrauma, such as pneumothorax.

\section{Measuring airflow obstruction}

Both patients and physicians tend to inaccurately gauge the level of airflow obstruction, which can lead to undertreatment and hence an unacceptable risk of relapse. .2.78-81,102,105,109 $^{6}$ Therefore, airflow obstruction must be measured objectively whenever possible, using either $\mathrm{FEV}_{1}$ or peak expiratory flow. Peak expiratory flow is an integral component of the Canadian Triage and Acuity Scale, a reliable and valid complaintbased triage tool developed by Canadian emergency nurses and physicians to prioritize the severity of a patient's condition and the timing of care in the emergency department. ${ }^{110,111}$ Measurements of airflow obstruction can help to guide therapy for acute asthma but are generally underutilized, ${ }^{12-16}$ despite their ease of performance. In one prospective study, more than $90 \%$ of patients presenting to the emergency department with acute asthma had valid spirometry measurements when the test was administered by trained personnel. ${ }^{112}$ Peak expiratory flow below $200 \mathrm{~mL}$ or less than $30 \%$ of predicted or $\mathrm{FEV}_{1}$ below $1.0 \mathrm{~L}$ or less than $25 \%$ of predicted at any time during an exacerbation of asthma indicates a high degree of obstruction and suggests the presence of elevated partial pressure of carbon dioxide $\left(\mathrm{PCO}_{2}\right)$ and the potential for fatigue of the respiratory muscles in particular and of the patient more generally. ${ }^{1,2,83}$

\section{Monitoring oxygen saturation}

Oxygen saturation should be continuously monitored by pulse oximetry, because cyanosis is a late sign reflecting severe hypoxemia (arterial partial pressure of oxygen $\left[\mathrm{PO}_{2}\right]$ $<40 \mathrm{~mm} \mathrm{Hg}$ ). For several reasons, oximetry is generally preferred over arterial blood gas analysis to assess oxygenation. Oximetry provides real-time, continuous measurements, whereas blood gases are monitored only intermittently and the samples take time to process. Oxyhemoglobin saturation is more meaningful than $\mathrm{PO}_{2}$ in assessing arterial oxygen content. Finally, oximetry is much easier to perform and is less painful for the patient. Nonetheless, there are some caveats to the use of pulse oximetry. ${ }^{113}$ To obtain reliable readings, the oximeter must be placed at a well-perfused site, and the pulse recorded by the oximeter should match the patient's pulse determined manually, as a sign that the oximeter signal is strong. Pulse oximeters may not provide reliable data for patients with global hypoperfusion or peripheral vasoconstriction or in rare cases in which carboxyhemoglobinemia or methemoglobinemia is a possibility. In the setting of acute asthma, determining arterial blood gas levels is indicated if there is concern that the patient is not improving and there are no oximetry data or if the data are thought to be unreliable. 
Arterial blood gas analysis is rarely needed for optimum management of acute asthma. However, blood gas levels, either arterial or venous, should be determined if the treating physician wishes to know the $\mathrm{PCO}_{2}$ and the $\mathrm{pH}$, or if spirometry or peak expiratory measurements are either not available or not possible for a patient whose condition is not improving or is deteriorating. Venous $\mathrm{pH}$ and venous $\mathrm{PCO}_{2}$ closely parallel arterial values and are adequate for identifying major acid-base disturbances. ${ }^{114-116}$ Venous gas measurement may be preferred over arterial blood gas analysis because the venous sample can be drawn by anyone skilled at venipuncture and is less painful for the patient. However, the venous $\mathrm{PO}_{2}$ and venous oxygen saturation should be ignored, as they are not representative of arterial values. The presence of hypercapnia can be inferred ${ }^{112}$ if the $\mathrm{FEV}_{1}$ is less than $25 \%$ of predicted or peak expiratory flow is less than $30 \%$ of predicted ${ }^{83,84}$ Hypercapnia during an acute asthma attack is a sign of severe airflow obstruction, but it does not always predict the need for assisted ventilation. ${ }^{49,50}$ Because most exacerbations of asthma are associated with hyperventilation causing hypocapnia and respiratory alkalosis, the finding of rising or normal arterial or venous $\mathrm{PCO}_{2}$ in the setting of acute asthma should be interpreted as a sign of impending respiratory failure and the possible need for assisted ventilation if it persists or worsens.

\section{Additional investigations}

Chest radiography should be performed if there is no response to therapy or if there is suspicion of an infectious cause, to identify or exclude unrecognized pneumothorax, pneumomediastinum or pneumonia. ${ }^{17}$ Obtaining an electrocardiogram is unnecessary for patients with acute asthma unless an acute coronary syndrome is suspected. Because most exacerbations of asthma are triggered by viral infections, sputum culture is not warranted unless the exacerbation is complicated or caused by obvious pneumonia.

Patients with combinations of the risk factors, signs and symptoms listed in Tables 1 and 2 are at high risk of death and should be monitored closely, particularly during the first one to two hours after arrival in the emergency department, even if their condition seems to improve with initial therapy. The early response of $\mathrm{FEV}_{1}$ or peak expiratory flow at 30 to 60 minutes after initial treatment is the best predictor of outcome. ${ }^{3,103,105}$

\section{The case continued}

At this point, a venous sample for blood gas analysis is obtained, and the patient attempts bedside peak flow measurement. The peak expiratory flow rate is about $25 \%$ of predicted. The venous $\mathrm{pH}$ is 7.32 , and the venous $P_{\mathrm{CO}_{2}}$ is $50 \mathrm{~mm} \mathrm{Hg}$. Furthermore, his bicarbonate level is $25 \mathrm{mmol} / \mathrm{L}$, which indicates that the hypercapnia is mostly acute (in relation to the current attack).

Because the patient has severe hypoxemia and is still in distress, despite initial treatment, a portable chest radiograph is ordered. Additional bronchodilator treatments (eight puffs each of salbutamol and ipratropium through a metered-dose inhaler with a valved holding chamber) are administered, along with
$2 \mathrm{~g}$ of magnesium sulphate, given intravenously over $20 \mathrm{~min}$ utes. Next, eight puffs of fluticasone propionate are given by metered dose inhaler and chamber. The chest radiograph shows extreme hyperinflation, but no signs of pneumothorax, mediastinal or subcutaneous emphysema, or pneumonia.

\section{Therapy for acute asthma}

The rapidity of response to initial therapy, as defined by changes in symptoms, signs and $\mathrm{FEV}_{1}$ or peak expiratory flow, may be a more useful measure of severity and the need for more aggressive therapy than the clinical status at presentation., ${ }^{2,3}$ Definitions of the terms "status asthmaticus," "lifethreatening" or "near fatal," and a "severe" episode of asthma are imprecise and should not be used to determine the level of therapy for acute asthma. Here, we use the term "moderate to severe asthma," by which we mean patients who have no clinical improvement with initial standard therapy and those whose presenting $\mathrm{FEV}_{1}$ or peak expiratory flow is less than $25 \%-30 \%$ of predicted.

The use of structured management plans and care maps for acute asthma has been shown to improve the use of objective measurements of airflow obstruction, increase the frequency of re-evaluation and reassessment, and reduce admission rates and length of stay in both the emergency department and the hospital. ${ }^{1,21,23,118-122}$ A structured management plan, the emergency department asthma care pathway, ${ }^{123}$ was recently prepared as part of the Asthma Plan of Action of the Ontario Ministry of Health and Long-Term Care ${ }^{124}$ and has been endorsed by the Canadian Thoracic Society and the Canadian Association of Emergency Physicians (Appendix 1, available at www.cmaj.ca/cgi/content/full/cmaj.080072/DC1). It was modelled in part on a similar plan in an earlier Canadian guideline $^{9}$ and other successful care maps for asthma..$^{21,23}$ Based on clinical criteria, including objective indices of airflow obstruction, this care map classifies the severity of acute asthma in four categories: mild, moderate, severe and lifethreatening. Each category is linked to the appropriate level in the Canadian Triage and Acuity Scale ${ }^{111}$ to guide the timing and nature of both initial assessment and therapy.

\section{Oxygen}

Hypoxia is the main cause of death in cases of acute asthma. Therefore, oxygen should be titrated to achieve oxygen saturation of at least $92 \%$. In general, supplemental oxygen will not suppress the drive to breathe in patients with acute asthma. Even though a slight rise in $\mathrm{PCO}_{2}$ may occur in response to oxygen therapy, this is of no clinical consequence. ${ }^{125}$

\section{Bronchodilators}

Rapid-acting inhaled $\beta_{2}$-adrenergic bronchodilators are firstline therapy for acute asthma. Because the optimal doses necessary to achieve maximal bronchodilation have not been defined, dosing is empiric and should be titrated using an objective measure of airflow obstruction, such as $\mathrm{FEV}_{1}$ or peak expiratory flow and clinical response. Recommended starting doses for bronchodilators and corticosteroids are unchanged from previous guidelines ${ }^{9-11}$ and are listed in 
Appendix 1. These drugs are safe for patients with acute asthma, and the heart rate usually falls with successful response to high doses of $\beta_{2}$-adrenergic bronchodilators in this setting. ${ }^{126}$ Furthermore, these drugs remain effective for patients who have self-treated unsuccessfully with the same agents before arrival in the emergency department. ${ }^{127}$ For patients with acute asthma, the inhaled route for bronchodilators is as good as or better than giving the same drugs intravenously. ${ }^{128-131}$ Concerns have been raised about the safety of intravenously administered epinephrine for acute asthma, ${ }^{132}$ but additional research is warranted. Intravenous administration of $\beta_{2}$-adrenergic bronchodilators or intramuscular or subcutaneous administration of epinephrine ${ }^{133}$ should be reserved for patients who are unable to use or who are unresponsive to the inhaled route. Such patients may require intubation and assisted ventilation.

Use of a pressurized metered-dose inhaler, preferably with a valved holding chamber or spacer, is at least as effective as wet nebulization in acute asthma ${ }^{134-136}$ and has the advantages of lower cost and ability to provide sequential doses more quickly (four to eight puffs in 2 minutes v. 10-20 minutes for a single nebulization). It also provides an opportunity for health care professionals to demonstrate correct use of the inhaler to the patient. When nebulization is used in severe asthma, continuous nebulization appears superior to intermittent nebulization for improvements in airflow obstruction and reduction in the need for admission to hospital. ${ }^{126,137,138}$

Although ipratropium bromide, a short-acting anticholinergic bronchodilator, has a slower onset of action than the $\beta_{2}$-adrenergic bronchodilators, randomized controlled trials and a meta-analysis have shown that combining these two agents results in greater improvements in lung function and a significant reduction in the need for admission to hospital than use of $\beta_{2}$-adrenergics alone, particularly for patients with severe airflow obstruction $\left(\mathrm{FEV}_{1} \leq 30 \%\right.$ of predicted). ${ }^{139,140}$ As with $\beta_{2}$-adrenergic bronchodilators, multiple dosing from a metered-dose inhaler with a valved holding chamber or delivery by multiple wet nebulizations is recommended (Appendix 1, available at www.cmaj.ca/cgi/content/full/cmaj $.080072 / \mathrm{DC} 1)$.

\section{Corticosteroids}

A dose of systemic corticosteroids should be administered within the first hour of treatment for acute asthma for all but patients with the mildest form of the disease. ${ }^{141}$ This therapy is particularly important for patients with severe asthma and those already receiving systemic corticosteroids, as recently confirmed by a large prospective study of asthma care that clearly demonstrated an inverse relation between need for hospital admission for acute asthma and time to administration of systemic corticosteroids. ${ }^{19}$ There is no evidence from controlled trials of an advantage for the intravenous over the oral route for corticosteroids in moderate to severe asthma. ${ }^{141,142}$ However, for patients with severe asthma who are too breathless to swallow an oral medication, who are experiencing nausea and vomiting, who have been intubated or who are unable to absorb oral medications, the intravenous route is preferred, at least initially. ${ }^{143}$ Optimal doses of systemic corti- costeroids for acute asthma have not been determined, but a meta-analysis and two systematic reviews suggested that doses equivalent to $30-80 \mathrm{mg}$ prednisone or methylprednisolone per day (150-400 mg hydrocortisone) are adequate and that higher doses do not seem to confer added advantage. ${ }^{142,144,145}$ Conventional doses for corticosteroids in acute asthma are listed in Appendix 1 (available at www.cmaj.ca /cgi/content/full/cmaj.080072/DC1).

Short-term administration of high-dose inhaled corticosteroids appears to accelerate recovery from acute asthma relative to systemic corticosteroids alone, particularly for patients with prolonged attacks and severe airflow obstruction. ${ }^{146-148}$ The rapid effect of inhaled corticosteroids in acute asthma may reflect a mechanism of action different from their traditional anti-inflammatory effects. It has been postulated that high-dose inhaled corticosteroids have topical nongenomic effects on the airway epithelium, including vasoconstriction and mucosal decongestion. ${ }^{147}$ Although it is possible that the addition of early, high-dose inhaled corticosteroids to systemic corticosteroids may confer additional benefit over the use of systemic corticosteroids alone, this has not yet been demonstrated, ${ }^{149}$ and additional research is required. There is, however, insufficient evidence to suggest that inhaled corticosteroids should replace systemic corticosteroids for the treatment of severe acute asthma. ${ }^{150}$

\section{Other therapies}

There is no support for the routine use of intravenous magnesium sulphate for acute asthma, but there is evidence that it is effective for patients with no response to first-line initial therapy and those with initial, severe airflow obstruction $\left(\mathrm{FEV}_{1}\right.$ or peak expiratory flow $<25 \%-30 \%$ predicted). ${ }^{151}$ The need for admission to hospital can be reduced and measurements of airflow improved with a single bolus dose (2 g intravenously for adults), which has only minor and infrequent adverse effects. The authors of one systematic review suggested that the combination of aerosolized, rather than intravenous, magnesium sulphate with standard care (systemic corticosteroids and inhaled $\beta_{2}$-adrenergic bronchodilators) lessened airflow obstruction and reduced admissions to hospital, ${ }^{152}$ but additional research is required before this route of delivery can be widely adopted.

Aminophylline is not recommended for acute asthma, as systematic reviews have consistently concluded that it confers no additional benefits over $\beta_{2}$-adrenergic bronchodilators alone. In addition, this drug has a narrow therapeutic margin and can cause substantial toxic effects, especially among hypoxemic patients. ${ }^{153,154}$

Despite the biological plausibility of modulation of turbulent airflow, systematic reviews have concluded that there is no role for the routine use of helium-oxygen mixtures in the initial treatment of acute asthma. ${ }^{155,156}$ There may, however, be benefit for patients with more severe airflow obstruction in whom aggressive first-line therapy has failed.

Acute wheezing and breathing distress may be caused by conditions other than asthma, some of which are listed in Box 1. These conditions should be considered if reassessment indicates no response to initial first-line therapy. 


\section{Treatment in pregnancy}

Exacerbations of asthma in pregnancy occur primarily in the late second trimester, the major triggers being viral infection and nonadherence with inhaled corticosteroid therapy. ${ }^{157}$ Pregnant women with acute asthma appear to be treated less often with systemic corticosteroids than nonpregnant patients and are more likely to report continuing asthma exacerbation after discharge from the emergency department. ${ }^{158}$ Because a severe asthma attack during pregnancy poses a greater risk to the fetus than do the adverse effects of asthma therapy, management of acute asthma in pregnancy should be no different than for nonpregnant patients.

\section{Outcome of the case}

The patient continues to receive additional bronchodilator therapy and gradually begins to improve. After two hours of therapy, he is breathing much more comfortably and is able to lie back, relax and sleep intermittently. Oxygen saturation is $92 \%$ with oxygen (4 L/min) administered by nasal cannulae, and he is no longer relying on his accessory muscles of breathing. Repeat spirometry and venous blood gas analysis reveal $\mathrm{FEV}_{1} 70 \%$ of predicted, peak expiratory flow $75 \%$ of predicted, $\mathrm{pH} 7.36$ and venous $\mathrm{PCO}_{2} 46 \mathrm{~mm} \mathrm{Hg}$. He asks to be discharged home, stating that he will take his inhaled corticosteroid more regularly in the future. However, despite the strong response to treatment, this patient is clearly at very high risk for fatal asthma, and an urgent consultation with the internist on call is arranged. After the consultation, the patient agrees to a short admission.

\section{Decision to admit}

Both clinical and lung function data are used in making the decision to admit a patient to hospital. Patients who continue to exhibit indications of severe asthma despite two to three hours of aggressive treatment should probably be admitted. Several studies have identified factors associated with relapse after discharge from the emergency department. ${ }^{159,160}$ The response to initial treatment is a better predictor of the safety of discharge from the emergency department or the need for hospital admission than is the apparent severity of an asthma exacerbation at presentation., ${ }^{3,103,105}$ Patients who present with pretreatment $\mathrm{FEV}_{1}$ or peak expiratory flow less than $25 \%-$ $30 \%$ of predicted and those with values after treatment that are less than $40 \%$ of predicted should usually be admitted to hospital. ${ }^{1,2,84,161}$ Patients who achieve $\mathrm{FEV}_{1}$ or peak expiratory flow of at least $60 \%$ of predicted can usually be discharged safely, ${ }^{84,162,163}$ provided adequate postdischarge care and follow-up are assured. For patients with intermediate $\mathrm{FEV}_{1}$ or peak expiratory flow values (i.e., $40 \%-60 \%$ of predicted) after treatment, decision-making must be individualized on the basis of the examining physician's knowledge of the patient's previous ability to manage an exacerbation, the likelihood that the patient will be adherent with medications and instructions, and the home or environmental circumstances to which the patient will return. If there are concerns about adherence, particularly historical features suggesting that the patient has a high risk of fatal asthma (Table 1), a cautious approach is prudent and a short admission (one or two days) may be indicated.

\section{Prevention of relapse}

To reduce the risk of relapse, most patients with moderate to severe asthma exacerbations and almost all patients who were previously taking inhaled corticosteroids should have a course of oral corticosteroids added at the time of discharge ${ }^{164,165}$ (Appendix 1, available at www.cmaj.ca/cgi/content/full /cmaj.080072/DC1, for dose and duration). Gradual tapering of the dose is unnecessary if the duration of oral corticosteroid use is less than one to two weeks. ${ }^{164,166}$

In a randomized controlled trial, the addition of high-dose inhaled corticosteroids to a course of oral corticosteroids at discharge was associated with a lower risk of relapse of the asthma exacerbation at 21 days than the use of oral corticosteroids alone. ${ }^{167}$ In a recent prospective study of asthma care in the emergency department, the risk of relapse at 28 days was inversely correlated with new prescriptions for inhaled corticosteroids at the time of discharge from the emergency department. ${ }^{19}$ Studies comparing the effectiveness of highdose inhaled and oral corticosteroids alone at the time of discharge from the emergency department for preventing relapse have not demonstrated any significant differences between these two management strategies, but additional studies are required. ${ }^{168,169}$ The effect of combinations of a long-acting $\beta_{2}$ adrenergic bronchodilator with an inhaled corticosteroid ${ }^{170}$ or an inhaled corticosteroid with a leukotriene receptor antagonist in reducing rates of relapse after discharge have also been studied, ${ }^{171}$ but there is currently insufficient evidence to recommend these approaches.

Adherence with medical advice after a hospital stay is reportedly poor among patients with acute asthma. ${ }^{160,172}$ For example, $12 \%$ to $22 \%$ of patients leaving the emergency department do not fill their prescriptions. ${ }^{173,174}$ Reasons for poor adherence are complex and include the cost of medications, a poor understanding of asthma and its therapy, limited access to health care professionals and psychological influences, including depression. ${ }^{175,176}$ If the risk of relapse is considered high and the likelihood of adherence with the postdischarge asthma management plan is thought to be low, options include a short stay in hospital or an intramuscular dose of corticosteroid at discharge (see Appendix 1 for details). ${ }^{177-179}$ The second of these approaches has been associated with a lower rate of relapse than placebo ${ }^{178}$ but appears equivalent to a short course of oral corticosteroids. ${ }^{164,177,179}$ The potential for adverse effects with corticosteroids does not appear to be higher with the intramuscular route than with oral administration. ${ }^{177}$

There are no clinical markers to identify individuals at risk for sudden onset of a near-fatal asthma exacerbation, but any patient who survives such an attack should be referred to an asthma specialist for a thorough investigation, including occupational and allergy assessment. Furthermore, it seems prudent to give an autoinjector for epinephrine to these individuals and to anyone with a history of anaphylaxis or angioedema.

The majority of patients who experience an asthma ex- 
Box 2: Key messages for assessment and monitoring of acute asthma*

\section{Assessment and monitoring}

- Historical features that identify patients at risk for potentially fatal asthma should be sought as part of the initial assessment of every acute exacerbation of asthma (grade B recommendation; level II-2 evidence).

- Features of the physical examination that characterize a severe and potentially fatal asthma attack should be sought as part of the initial assessment of every acute exacerbation of asthma (grade B recommendation; level II-2 evidence).

- Objective measurement of airflow obstruction, by means of spirometry or measurement of peak expiratory flow, is recommended for optimal management of acute asthma (grade B recommendation; level II-1 evidence).

- Measurement of arterial or venous blood gases is recommended in the presence of severe airflow obstruction, particularly if the forced expiratory volume in 1 second ( $\left(\mathrm{FV}_{1}\right)$ or the peak expiratory flow is less than $40 \%$ of predicted or if the patient has had suboptimal response to first-line therapy (grade B recommendation; level II-2 evidence).

- Continuous monitoring of oxyhemoglobin saturation by transcutaneous pulse oximetry should be undertaken for all patients with acute exacerbation of asthma.

- Patients deemed at high risk for potentially fatal asthma should be closely monitored in a critical care area.

- Routine chest radiography is not required, especially if there is an appropriate response to bronchodilator therapy.

- Electrocardiography is not routinely required unless there is a high degree of suspicion for ischemic heart disease that might be aggravated by the exacerbation or its treatment.

- Routine examination and culture of sputum is not required.

*All grade I recommendations, based on level II-3 or level III evidence, unless indicated otherwise.

acerbation will have had poor asthma control preceding the exacerbation. Whether the patient is discharged from the emergency department or admitted to hospital, health care professionals treating the exacerbation should review with the patient what is meant by control of asthma and any barriers to achieving asthma control that may have existed before the exacerbation. Patient education should include the role of medications (especially the importance of anti-inflammatory therapy and the proper use of inhalers) and the importance of avoiding allergens, irritants and workplace exposures if appropriate. ${ }^{26}$

\section{Action plans}

There is strong evidence to support the role of action plans detailing how to prevent and manage future exacerbations. ${ }^{99,180,181}$ Written action plans specifying an increase in inhaled corticosteroid dose and a concurrent course of oral corticosteroids are effective in reducing admissions to hospital for acute asthma. ${ }^{99}$ In contrast, verbal action plans are inadequate: in one study, the odds ratio for death from asthma was four times lower with a written action plan than with a verbal action plan. ${ }^{73}$ In general, written action plans contain four essential elements: when to increase therapy, how to increase therapy, the duration of increased therapy and the point at which to cease self-management and seek medical help. ${ }^{180}$ Canadian data have confirmed that simply handing out an action plan, without educational discussion, is ineffective in improving asthma control. ${ }^{182}$ For some patients, the provision of an action plan based on use of a peak flow meter and asthma education can significantly reduce the risk of relapse, ${ }^{183}$ but for most patients, action plans based on selfmonitoring of symptoms seem to be just as efficacious as plans based on peak flow. ${ }^{184}$ Many examples of asthma action plans are available (see, for example, www.asthmaguidelines.com or www.lung.ca, or the sample action plan presented as an appendix to an earlier article in this series $\left.{ }^{185}\right)$.

Reassessment and re-evaluation are crucial elements in achieving and maintaining control of asthma. Therefore, optimal management of an asthma exacerbation includes referral to the patient's primary care physician, if possible, and/or to an asthma educator or asthma specialist, if available. In one randomized controlled trial, a scheduled appointment with a primary care provider, initiated in the emergency department, was associated with a higher prevalence of primary care follow-up $(65 \%)$ than either advice alone $(42 \%)$ or telephone reminders to seek follow-up (48\%). ${ }^{92}$ However, at one year, there were no differences among groups in terms of use of inhaled corticosteroids, visits to the emergency department or quality of life. Facilitated referral to an asthma specialist after treatment of acute asthma in the emergency department reduced the likelihood of relapse during the ensuing six months. ${ }^{91}$

\section{Inpatient treatment of acute asthma}

The principles of inpatient treatment of acute asthma are the same as those outlined for therapy in the emergency department. Several studies have demonstrated that the use of structured care plans and observation units is associated with reduced rates of hospital admission and reduced lengths of stay. ${ }^{119,121,186}$

Patients who require admission to hospital for asthma exacerbation have clearly demonstrated poor asthma control and should be referred to an asthma specialist. ${ }^{91,99,187}$ The goals of such referral are to enhance the prospects for success of education related to self-management, which will involve development of a written action plan, to review any barriers to asthma control and to improve the likelihood of adherence with follow-up. If possible, such consultation should take place before the patient is discharged.

\section{Gaps in knowledge and care}

The key messages for the nonventilatory management of asthma in adults in the emergency department are presented in Box 2, Box 3 and Box 4.

Gaps in knowledge exist in several areas, representing opportunities for future research in the assessment and management of acute asthma. 


\section{Box 3: Key messages for treatment of acute asthma*}

- The aggressiveness of treatment should be based on the degree of airflow obstruction and symptoms.

- The use of structured management plans, including care maps, is recommended for the treatment of acute asthma in the emergency department (grade A recommendation; level I evidence).

- Oxygen should be administered to all patients with acute asthma, with the goal of maintaining oxygen saturation at $92 \%$ or above.

- Rapid-acting inhaled $\beta_{2}$-adrenergic bronchodilators are first-line therapy for acute asthma.

- Bronchodilators should be administered by inhalation and are equally effective with administration by nebulizer or by pressurized metered-dose inhaler, preferably with a valved holding chamber (grade A recommendation; level I evidence).

- The combined use of short-acting anticholinergic and $\beta_{2}$-adrenergic bronchodilators is recommended for patients with moderate to severe acute asthma (grade A recommendation; level I evidence).

- A single dose of systemic corticosteroids within one hour of presentation to the emergency department is recommended for patients with moderate to severe acute asthma (grade A recommendation, level I evidence).

- Early, frequent use of high doses of inhaled corticosteroids, in addition to systemic corticosteroids, may be considered for patients with moderate to severe acute asthma.

- Intravenous administration of magnesium sulphate is recommended for patients with severe acute asthma that is unresponsive to therapy with bronchodilators and systemic corticosteroids (grade B recommendation; level II-I evidence).

- Intravenous administration of aminophylline is not recommended during the first four hours of treatment (grade E recommendation; level I evidence).

- Helium-oxygen mixtures should be reserved for patients with acute asthma that is unresponsive to standard firstline therapy who are likely to require assisted ventilation (grade $\mathrm{C}$ recommendation; level I evidence).

- Exacerbations of asthma during pregnancy should be treated aggressively in the same manner as for nonpregnant individuals.

- Patients whose acute asthma is not responding to appropriate therapy should be reviewed for the adequacy of current therapy and for conditions that may mimic or complicate asthma.

*All grade I recommendations, based on level II-3 or level III evidence, unless indicated otherwise.

Research is needed into ways of identifying the specific phenotype of asthma that is associated with high risk for potentially fatal asthma. ${ }^{31}$ Sudden asphyxic asthma ${ }^{30}$ may represent a particular phenotype, and efforts are needed to better characterize this relatively rare occurrence and its risk factors. Although it is known that poor preventive management of asthma predisposes people to poor asthma control and heightens the risk of death from asthma, novel methods for monitoring the adequacy of anti-inflammatory control of asthma should be developed and simplified for widespread use. ${ }^{188}$ This might entail the development of serologic markers, simplified management of
Box 4: Key messages for subsequent care of patients with acute asthma*

\section{Decision to admit or discharge}

- Measurement of peak expiratory flow or forced expiratory volume in 1 second $\left(\mathrm{FEV}_{1}\right)$ is recommended to help in the decision to admit a patient with acute asthma to hospital or to safely discharge him or her from the emergency department (grade B recommendation; level II-1 evidence).

- Any patient with persisting signs and symptoms of severe asthma after two to three hours of appropriate and aggressive treatment should be admitted to hospital.

\section{Prevention of relapse after discharge}

- For patients with moderate to severe acute asthma, a short course of oral corticosteroids is recommended upon discharge from the emergency department to help reduce the risk of relapse of the asthma exacerbation (grade $A$ recommendation; level I evidence).

- The combined use of high-dose inhaled corticosteroids and oral corticosteroids at the time of discharge from the emergency department is recommended to reduce the risk of relapse of the asthma exacerbation (grade $A$ recommendation; level I evidence).

- If the risk for nonadherence with oral corticosteroid therapy after discharge from the emergency department and the risk of relapse are thought to be high, consideration may be given to administering an intramuscular dose of corticosteroid, instead of a course of oral corticosteroid (grade B recommendation; level II-2 evidence).

- People who survive sudden-onset, near-fatal exacerbations should be identified, their history should be studied for risk factors, and they should be given an autoinjector for epinephrine.

- Health care professionals should take the opportunity provided by an exacerbation of asthma to educate the patient about the definition of and how to achieve control of asthma.

- Upon discharge from the emergency department or hospital, every patient should have a written management plan (action plan) detailing how to prevent and manage future exacerbations (grade B recommendation; level II-1 evidence).

- Efforts should be directed at ensuring follow-up with a health care professional after a visit to the emergency department for management of an exacerbation of asthma (grade A recommendation; level I evidence).

- Consultation with an asthma specialist is recommended for patients who have been admitted to hospital for asthma.

*All grade I recommendations, based on level II-3 or level III evidence, unless indicated otherwise.

cytologic examination of induced sputum, or reliable and practical methods of analyzing exhaled breath condensate.

Wider use of structured management plans or care maps and observation units would help to standardize care and should be incorporated into the criteria for accreditation of hospitals. Strategies should be developed to increase the use of spirometry and the measurement of peak expiratory flow in the emergency department. ${ }^{19,20}$ Educational strategies to improve the early recognition of potentially fatal exacerbations and to promote appropriate and timely aggressive intervention should also be developed. 
The combination of inhaled $\beta_{2}$-adrenergic and anticholinergic bronchodilators is useful in the management of acute asthma ${ }^{139,140}$ but is currently not available in metered-dose inhaler format in Canada. Development of such a combination inhaler should be pursued as a means of making inhaled therapy of acute asthma more efficient. Research is needed on the role of early use of high-dose inhaled corticosteroids in addition to systemic corticosteroids for acute asthma, ${ }^{147}$ as is research on the potential roles of aerosolized magnesium ${ }^{152}$ and intravenous administration of leukotriene receptor antagonists $^{189}$ in this setting. Additional research is also needed on the role of helium-oxygen to improve the delivery of inhaled asthma medications, ${ }^{155}$ as is research to develop novel ways of controlling airway inflammation in asthma, through low-dose theophylline $\mathrm{e}^{100}$ and the new phosphodiesterase inhibitors ${ }^{191}$ and through the development of newer anti-inflammatory agents.

\section{This article has been peer reviewed.}

Competing interests: Diane Lougheed has served on GlaxoSmithKline's National Respiratory Epidemiology Advisory Board. She has received research grants from AllerGen NCE, Ception Therapeutics, Topigen Pharmaceuticals, the Ontario Ministry of Health and Long-Term Care, the Ontario Thoracic Society and the Queen's University William M. Speare Endowment/Start Memorial Fund. Brian Rowe has received research funding and speaker fees from GlaxoSmithKline and AstraZeneca. He is supported by the 21st Century Canada Research Chairs program through the government of Canada. Mark FitzGerald has served on advisory boards for GlaxoSmithKline, AstraZeneca, Novartis, Pfizer, Boehringer-Ingelheim, Altana, Merck and Topigen. He has also been a member of speakers' bureaus for GlaxoSmithKline, AstraZeneca, Boehringer-Ingelheim, Pfizer and Merck. He has received research funding paid directly to the University of British Columbia from the Canadian Institutes of Health Research, AstraZeneca, GlaxoSmithKline, Boehringer-Ingelheim, Merck, Wyeth, Schering, Genentech and Topigen. Mark FitzGerald is a member of the Global Initiative for Asthma (GINA) and is chair of the GINA Science Committee. Alan Kaplan has received honoraria for talks from AstraZeneca, GlaxoSmithKline, Nycomed, Boehringer-Ingelheim and Pfizer. He has served on advisory boards for Merck Frosst, Nycomed, AstraZeneca and Boehringer-Ingelheim. He has received travel reimbursement to meetings of the European Respiratory Society from Merck and AstraZeneca. Andrew McIvor and Rick Hodder have attended advisory board meetings and provided continuing medical education for which they have received honoraria from pharmaceutical companies involved in asthma management: AstraZeneca, Boehringer-Ingelheim, Graceway, GlaxoSmithKline, Novartis, Merck Frosst and Pfizer.

Contributors: All authors contributed to the development and editing of the publication, and all approved the final version submitted for publication.

Funding: The Canadian Thoracic Society has received funding to facilitate the knowledge translation activities of the CTS Asthma Committee from AstraZeneca Canada, GlaxoSmithKline Inc., Merck Frosst Canada and Novartis Pharmaceuticals. None of the sponsors played a role in the collection, review, analysis or interpretation of the scientific literature or in any decisions regarding the key messages presented in the case studies.

\section{REFERENCES}

1. Aldington S, Beasley R. Asthma exacerbations 5: Assessment and management of severe asthma in adults in hospital. Thorax 2007:62:447-58.

2. McFadden ER Jr. Acute severe asthma. Am J Respir Crit Care Med 2003;168:74059

3. FitzGerald JM. The management of acute life-threatening asthma. Eur Respir Monit 2003;23:396-408.

4. Corbridge SJ, Corbridge TC. Severe exacerbations of asthma. Crit Care Nurs $Q$ 2004;27:207-28.

5. Corbridge TC, Hall JB. The assessment and management of adults with status asthmaticus. Am J Respir Crit Care Med 1995;151:1296-316.

6. Restrepo RD, Peters J. Near-fatal asthma: recognition and management. Curr Opin Pulm Med 2008;14:13-23.
7. Global strategy for asthma management and prevention. Global Initiative for Asthma; 2008. Available: www.ginasthma.com/Guidelineitem.asp?11=2\&12 $=1 \&$ intId=60 (accessed 2009 Sep. 7).

8. British Thoracic Society; Scottish Intercollegiate Guidelines Network. British guideline on the management of asthma: a national clinical guideline. London (UK): The Society; 2008. Available: www.sign.ac.uk/pdf/sign101.pdf (accessed 2009 Aug. 26)

9. Beveridge RC, Grunfeld AF, Hodder RV, et al. Guidelines for the emergency management of asthma in adults. CAEP/CTS Asthma Advisory Committee. Canadian Association of Emergency Physicians and Canadian Thoracic Society. CMAJ 1996;155:25-37.

10. Boulet LP, Becker A, Bérubé D, et al. Canadian asthma consensus report, 1999. CMAJ 1999;160(11 Suppl):S1-62.

11. Boulet LP, Bai T, Becker A, et al. What is new since the last (1999) Canadian Asthma Consensus Guidelines? Can Respir J 2001;8 Suppl A:5A-27A.

12. Gervais P, Larouche I, Blais L, et al. Asthma management at discharge from the emergency department: a descriptive study. Can Respir J 2005;12:219-22.

13. Reid J, Marciniuk D, Cockroft D. Asthma management in the emergency department. Can Respir J 2000; 7:255-60.

14. Salmeron S, Liard R, Elkharrat D, et al. Asthma severity and adequacy of management in accident and emergency departments in France: a prospective study. Lancet 2001;358:629-35.

15. FitzGerald JM, Hargreave FE. Acute asthma: emergency department management and prospective evaluation of outcome. CMAJ 1990;142:591-5.

16. Grunfeld A, Beveridge RC, Berkowitz J, et al. Management of acute asthma in Canada: an assessment of emergency physician behaviour. J Emerg Med 1997;15: 547-56.

17. Rowe BH, Bota G, Clark S, et al. Comparison of Canadian versus American emergency department visits for acute asthma. Can Respir J 2007;14:331-7.

18. Krym VF, Crawford B, MacDonald RD. Compliance with guidelines for emergency management of asthma in adults: experience at a tertiary care teaching hospital. CJEM 2004;6:321-6.

19. Lougheed MD, Garvey N, Chapman KR, et al. Variations and gaps in management of acute asthma in Ontario emergency departments. Chest 2009;135:724-36.

20. Olajos-Clow J, Szpiro K, Julien B, et al. Emergency department adult asthma care pathway: healthcare providers' perceived utility and barriers to implementation. Adv Emerg Nurs J 2009;31:44-53.

21. Mackey D, Myles M, Spooner $\mathrm{CH}$, et al. Changing the process of care and practice in acute asthma in the emergency department: experience with an asthma care map in a regional hospital. CJEM 2007;9:353-65.

22. Rowe BH, Camargo CA Jr; Multicenter Airway Research Collaboration (MARC) Investigators. The use of magnesium sulfate in acute asthma: rapid uptake of evidence in North American emergency departments. J Allergy Clin Immunol 2005 ; 117:53-8.

23. Rowe $\mathrm{BH}$, Chahal AM, Spooner $\mathrm{CH}$, et al. Increasing the use of anti-inflammatory agents in acute asthma in the emergency department: experience with an asthma care map. Can Respir J 2008;15:20-6.

24. Krahn MD, Berka C, Langlois P, et al. Direct and indirect costs of asthma in Canada, 1990. CMAJ 1996;154:821-31.

25. Lougheed MD, Garvey N, Chapman KR, et al. The Ontario Asthma Regional Variation Study: emergency department visit rates and the relation to hospitalization rates. Chest 2006;129:909-17.

26. Tarlo SM, Balmes J, Balkissoon R, et al. Diagnosis and management of workrelated asthma: American College of Chest Physicians consensus statement. Chest 2008; $134: 1-141$

27. Turner MO, Noertjojo K, Vedal S, et al. Risk factors for near-fatal asthma: a casecontrol study in hospitalized patients with asthma. Am J Respir Crit Care Med 1998;157:1804-9.

28. Rodrigo GJ, Rodrigo C. Rapid onset asthma attack: a prospective cohort study about characteristics and response to emergency department treatment. Chest 2000;118:1547-52

29. Kolbe J, Fergusson W, Garrett J. Rapid onset asthma: a severe but uncommon manifestation. Thorax 1998;53:241-7.

30. Wasserfallen J, Schaller MD, Feihl F, et al. Sudden asphyxic asthma: A distinct entity? Am Rev Respir Dis 1990;142:108-11.

31. Romagnoli M, Caramori G, Braccioni F, et al. Near-fatal asthma phenotype in the ENFUMOSA cohort. Clin Exp Allergy 2007;37:552-7.

32. McFadden ER Jr. Fatal and near-fatal asthma. N Engl J Med 1991;324:409-11.

33. Sur S, Crotty T, Kephart G, et al. Sudden onset fatal asthma. A distinct entity with few eosinophils and relatively more neutrophils in the airway submucosa? Am Rev Respir Dis 1993:148:713-9.

34. Hogg RS, Schecter MT, Montaner JSG, et al. Asthma mortality in Canada, 1946 to 1990. Can Respir J 1995;2:61-6.

35. Life and breath: respiratory disease in Canada. Ottawa: Public Health Agency of Canada; 2007. Available: www.phac-aspc.gc.ca/publicat/2007/lbrdc-vsmrc/indexeng.php (accessed 2009 Sep. 14)

36. Boulet LP, Deschesnes F, Turcotte H, et al. Near fatal asthma: clinical and physiologic features, perception of bronchoconstriction, and psychologic profile. J Allergy Clin Immunol 1991;88:838-46.

37. Harrison B, Stephenson P, Mohan G, et al. An ongoing confidential enquiry into asthma deaths in the eastern region of the UK, 2001-2003. Prim Care Respir J 2005;14:303-13.

38. Alvarez GG, Schulzer M, Jung D, et al. A systematic review of risk factors associated with near-fatal asthma. Can Respir J 2005;12:265-70. 
39. Rea HH, Scragg R, Jackson R, et al. A case-control study of deaths from asthma. Thorax 1986;41:833-9.

40. Rea HH, Sears MR, Beaglehole R, et al. Lessons from the national asthma mortality study: circumstances surrounding death. NZ Med J 1987;100:10-3.

41. Koga T, Oshita Y, Kamimura T, et al. Characterisation of patients with frequent exacerbation of asthma. Respir Med 2006;100:273-8.

42. Kolbe J, Fergusson W, Vamos M, et al. Case-control study of severe life threatening asthma (SLTA) in adults: demographics, health care, and management of the acute attack. Thorax 2000;55:1007-15.

43. Omachi TA, Iribarren C, Sarkar U, et al. Risk factors for death in adults with severe asthma. Ann Allergy Asthma Immunol 2008;101:130-6.

44. Crane J, Pearce N, Bugess C, et al. Markers of risk of asthma death or readmission in the 12 months following a hospital admission for acute asthma. Int J Epidemio $1992 ; 21: 737-44$

45. Miller TP, Greenberger PA, Patterson R. The diagnosis of potentially fatal asthma in hospitalized adults. Patient characteristics and increased severity of asthma. Chest 1992;102:515-8.

46. Serrano J, Plaza V, Sureda B, et al. Alexithymia: a relevant psychological variable in near-fatal asthma. Eur Respir J 2006;28:296-302.

47. Rothwell RP, Rea HH, Sears MR, et al. Lessons from the national asthma mortality study: deaths in hospital. $N$ Z Med $J$ 1987;100:199-202.

48. Kallenbach JM, Frankel AH, Lapinsky SE, et al. Determinants of near fatality in acute severe asthma. Am J Med 1993;95:265-72.

49. Mountain RD, Sahn SA. Clinical features and outcome in patients with acute asthma presenting with hypercapnia. Am Rev Respir Dis 1988;138:535-9.

50. Molfino NA, Slutsky AS. Near-fatal asthma. Eur Respir J 1994;7:981-90.

51. Spitzer WO, Suissa S, Ernst P, et al. The use of beta-agonists and the risk of death and near death from asthma. N Engl J Med 1992;326:501-6.

52. Suissa S, Blais L, Ernst P. Patterns of increasing beta agonist use and risk of fatal and near fatal asthma. Eur Respir J 1994;7:1602-9.

53. Suissa S, Ernst P, Boivin JF, et al. A cohort analysis of excess mortality in asthma and the use of inhaled beta-agonists. Am J Respir Crit Care Med 1994:149:604-10.

54. Ernst P, Spitzer WO, Suissa S, et al. Risk of fatal and near-fatal asthma in relation to inhaled corticosteroid use. JAMA 1992;268:3462-4.

55. Cates CJ, Cates MJ. Regular treatment with salmeterol for chronic asthma: serious adverse events. Cochrane Database Syst Rev 2008;(3):CD006363.

56. Cates CJ, Cates MJ, Lasserson TJ. Regular treatment with formoterol for chroni asthma: serious adverse events. Cochrane Database Syst Rev 2008;(4):CD006923.

57. Nelson HS, Weiss ST, Bleecker ER, et al. The Salmeterol Multicenter Asthm Research Trial: a comparison of usual pharmacotherapy for asthma or usual pharmacotherapy plus salmeterol. Chest 2006;129:15-26.

58. Salpeter SR, Buckley NS, Ormiston TM, et al. Meta-analysis: effect of long-acting beta-agonists on severe asthma exacerbations and asthma-related deaths. Ann Intern Med 2006;144:904-12.

59. Yoshimine F, Hasegawa T, Suzuki E, et al. Contribution of aspirin-intolerant asthma to near fatal asthma based on a questionnaire survey in Niigata Prefecture, Japan. Respirology 2005;10:477-84.

60. Picado C, Castillo JA, Montserrat JM, et al. Aspirin-intolerance as a precipitating factor of life-threatening attacks of asthma requiring mechanical ventilation. Eur Respir J 1989;2:127-9.

61. Eisner MD, Katz PP, Yelin EH, et al. Risk factors for hospitalization among adult with asthma: the influence of sociodemographic factors and asthma severity. Respir Res 2001;2:53-60.

62. Magadle R, Berar-Yanay N, Weiner P. The risk of hospitalization and near-fata and fatal asthma in relation to the perception of dyspnea. Chest 2002;121:329-33.

63. Plaza V, Giner J, Picado C, et al. Control of ventilation, breathlessness perception and alexithymia in near-fatal asthma. J Asthma 2006;43:639-44

64. Kikuchi Y, Okabe S, Tamura G, et al. Chemosensitivity and perception of dyspnea in patients with a history of near-fatal asthma. N Engl J Med 1994;330:1329-34.

65. Kolbe J, Fergusson W, Vamos M, et al. Case-control study of severe life threatening asthma (SLTA) in adults: psychological factors. Thorax 2002;57:317-22.

66. ten Brinke A, Sterk PJ, Masclee AA, et al. Risk factors of frequent exacerbation in difficult-to-treat asthma. Eur Respir J 2005;26:812-8

67. Joseph KS, Blais L, Ernst P, et al. Increased morbidity and mortality related to asthma among asthmatic patients who use major tranquillisers. BMJ 1996;312:79-81.

68. Campbell DA, Yelloelees PM, McLennan G, et al. Psychiatric and medical features of near fatal asthma. Thorax 1995;50:254-9.

69. Alvarez GG, FitzGerald JM. A systematic review of the psychological risk factor associated with near fatal asthma or fatal asthma. Respiration 2007;74:228-36.

70. Carr W, Zeitel L, Weiss K. Variations in asthma hospitalizations and deaths in New York City. Am J Public Health 1994;82:59-65.

71. American Lung Association Epidemiology and Staistics Unit Research and Program Services. Trends in asthma morbidity and mortality. Washington (DC) American Lung Association; 2006. Available from: www.lung.usa.org (registration required).

72. Eisner MD, Iribarren $\mathrm{C}$. The influence of cigarette smoking on adult asthma outcomes. Nicotine Tob Res 2007;9:53-6.

73. Abramson MJ, Bailey MJ, Couper FJ, et al. Are asthma medications and management related to deaths from asthma? Am J Respir Crit Care Med 2001;163:12-8.

74. Levenson T, Greenberger PA, Donoghue ER, et al. Asthma deaths confounded by substance abuse: an assessment of fatal asthma. Chest 1996;110:604-10.

75. Johnson AJ, Nunn AJ, Somner AR, et al. Circumstances of death from asthma. $\mathrm{Br}$ Med J (Clin Res Ed) 1984;288:1870-2.

76. FitzGerald JM, Macklem PT. Proceedings of a workshop on near fatal asthma. Can Respir J 1995;2:113-26.
77. FitzGerald JM, Macklem P. Fatal asthma. Annu Rev Med 1996:47:161-8.

78. Barnes PJ. Blunted perception and death from asthma. N Engl J Med 1994;330:1383-4

79. Lougheed M, O'Donnell D. Dyspnea in asthma. In: Mahler D, O'Donnell D, editors. Dyspnea: mechanisms, measurement and management. Boca Ratan (FL): Taylor and Francis Group; 2005. p. 59-86.

80. Lougheed MD. Variability in asthma: symptom perception, care, and outcomes. Can J Physiol Pharmacol 2007;85:149-54.

81. Barnes PJ. Poorly perceived asthma. Thorax 1992;47:408-9.

82. Brenner BE, Abraham E, Simon RR. Position and diaphoresis in acute asthma. Am J Med 1983;74:1005-9.

83. Nowak RM, Tomlanovich MC, Sarker DD, et al. Arterial blood gases and pulmonary function testing in acute bronchial asthma. Predicting patient outcomes. JAMA 1983;49:2043-6.

84. Nowak RM, Gordon KR, Wroblewski DA. Spirometric evaluation of acute bronchial asthma. JACEP 1979;8:9-12.

85. Soli CJ, Smally AJ. Vocal cord dysfunction: an uncommon cause of stridor J Emerg Med 2005;28:31-3.

86. Mikita JA, Mikita CP. Vocal cord dysfunction. Allergy Asthma Proc 2006;27:411-4

87. Bahrainwala AH, Simon MR. Wheezing and vocal cord dysfunction mimicking asthma. Curr Opin Pulm Med 2001;7:8-13.

88. Emond SD, Reed CR, Graff LG IV, et al.; MARC Investigators Asthma education in the emergency department. Ann Emerg Med 2000;36:204-11.

89. Coté J, Bowie D, Robichaud P, et al. Evaluation of two different educational interventions for adult patients consulting with an acute asthma exacerbation. Am J Respir Crit Care Med 2001;163:1415-9.

90. Szpiro KA, Harrison MB, VandenKerkhoff EG, et al. Asthma education delivered in an emergency department and an asthma education centre: a feasibility study. Adv Emerg Nurs J 2009;31:65-77.

91. Zeiger RS, Heller S, Mellon MH, et al. Facilitated referral to asthma specialists reduces relapses in emergency room visits. J Allergy Clin Immunol 1991;87:1160-8.

92. Baren JM, Boudreaux ED, Brenner BE, et al. Randomized controlled trial of emergency department interventions to improve primary care follow-up for patients with acute asthma. Chest 2006;129:257-65.

93. Hodder R, Lougheed MD, FitzGerald JM, et al. Management of acute asthma in adults in the emergency department: assisted ventilation. CMAJ 2009. DOI:10.1503/cmaj.080073. In press.

94. Schatz M, Kazzi AAN, Brenner B, et al. Joint task force report: supplemental recommendations for the management and follow-up of asthma exacerbations. Proc Am Thorac Soc 2009;6:353-93.

95. Canadian Task Force on Preventive Health Care. New grades for recommendations from the Canadian Task Force on Preventive Health Care. CMAJ 2003;169:207-8.

96. Kaplan A, Balter M, Bell A, et al. Diagnosis of asthma in adults. CMAJ 2009. DOI:10.1503/cmaj.080006.

97. Schull MJ, Ferris LE, Tu JV, et al. Problems for clinical judgement 3. Thinking clearly in an emergency. CMAJ 2001;164:1170-5.

98. FitzGerald JM, Turner MO. Delivering asthma education to special high risk groups. Patient Educ Couns 1997;32(1 Suppl):S77-86.

99. FitzGerald JM, Gibson PG. Asthma exacerbations. 4: Prevention. Thorax 2006;61: 992-9.

100. Greenberger PA, Miller TP, Lifschultz B. Circumstances surrounding death from asthma in Cook County (Chicago) Illinois. Allergy Proc 1993;14:321-6.

101. Nannini LJ, Zaietta GA, Guerrera AJ, et al. Breath-holding test in subjects with near fatal asthma. A new index for dyspnea perception. Respir Med 2007;101:246-53

102. McFadden ER Jr, Kiser R, DeGroot WJ. Acute bronchial asthma: relations between clinical and physiologic manifestations. N Engl J Med 1973;288:221-5.

103. Rodrigo GJ, Rodrigo C, Hall JB. Acute asthma in adults: a review. Chest 2004 125:1081-102.

104. Fischl MA, Pitchenik A, Gardner LB. An index predicting relapse and need for hospitalization in patients with acute bronchial asthma. N Engl J Med 1981;305:783-9.

105. Rodrigo G, Rodrigo C. Early prediction of poor response in acute asthma patients in the emergency room. Chest 1998;114:1016-21.

106. Knowles GK, Clark TJ. Pulsus paradoxus as a valuable sign indicating severity of asthma. Lancet $1973 ; 2: 1356-9$

107. Jay GD, Onuma K, Davis R, et al. Analysis of physician ability in the measurement of pulsus paradoxus by sphygmomanometry. Chest 2000;118:348-52.

108. Shim CS, Williams MH Jr. Relationship of wheezing to the severity of obstruction in asthma. Arch Intern Med 1983;143:890-2.

109. Shim CS, Williams MH Jr. Evolution of the severity of asthma: patients versus physicians. Am J Med 1980;68:11-3.

110. Beveridge R. CAEP issues. The Canadian Triage and Acuity Scale: a new and critical element in health care reform. Canadian Association of Emergency Physicians. J Emerg Med 1998;16:507-11.

111. Policies/guidelines: CTAS [Canadian Triage and Acuity Scale]. Ottawa: Canadian Association of Emergency Physicians; 2009. Available: www.caep.ca/template asp?id=B795164082374289BBD9C1C2BF4B8D32 (accessed 2009 Sep. 25).

112. Silverman RA, Flaster E, Enright PL, et al. $\mathrm{FEV}_{1}$ performance among patients with acute asthma. Chest 2007;131:164-71.

113. Soubani AO. Noninvasive monitoring of oxygen and carbon dioxide. Am J Emerg Med 2001;19:141-6.

114. Rang LC, Murray HE, Wells GA, et al. Can peripheral venous blood gases replace arterial blood gases in emergency department patients? CJEM 2002;4:7-15.

115. Gennis PR, Skovron ML, Aronson ST, et al. The usefulness of peripheral venous blood in estimating acid-base status in acutely ill patients. Ann Emerg Med 1985; 14:845-9.

116. Kelly AM, Kyle E, McAlpine R. Venous $\mathrm{PCO}_{2}$ and $\mathrm{pH}$ can be used to screen for 
significant hypercarbia in emergency patients with acute respiratory disease. J Emerg Med 2002;22:15-9.

117. Zieverink SE, Harper AP, Holden RW, et al. Emergency room radiography of asthma: an efficacy study. Radiology 1982;145:27-9.

118. Wrenn K, Rodewald L, Lumb E, et al. The use of structured, complaint-specific patient encounter forms in the emergency department. Ann Emerg Med 1993;22: $805-12$

119. Emond SD, Woodruff PG, Lee EY, et al. Effect of an emergency department asthma program on acute asthma care. Ann Emerg Med 1999;34:321-5.

120. McFadden ER Jr, Elsanadi N, Dixon L, et al. Protocol therapy for acute asthma: therapeutic benefits and cost savings. Am J Med 1995;99:651-6.

121. Goldberg R, Chan L, Haley P, et al. Critical pathway for the emergency department management of acute asthma: effect of resource utilization. Ann Emerg Med 1998;31:562-7.

122. Guttmann A, Zagorski B, Austin P, et al. Effectiveness of emergency department asthma management strategies on return visits in children: a population-based study. Pediatrics 2007;120:e1402-10.

123. Emergency department asthma care pathway. Toronto: Ontario Lung Association, Ministry of Health and Long-Term Care; 2009. Available: www.on.lung.ca /Health-Care-Professionals/EDACP/emerg_path_dl.php (accessed 2009 Sep. 24).

124. Garvey N, Lougheed D. Asthma in Ontario: Ontario's asthma plan of action. In: Boulet LP, Becker A, Bowie D, et al., editors. Implementing practice guidelines: a workshop on guidelines dissemination and implementation with a focus on asthma and COPD. Can Respir J 2006;13(Suppl A):32A-34A

125. Rodrigo GJ, Verde Rodriguez M, Peregalli V, et al. Effects of short-term $28 \%$ and $100 \%$ oxygen on $\mathrm{PaCO}_{2}$ and peak expiratory flow rate in acute asthma: a randomized trial. Chest 2003;124:1312-7.

126. Lin RY, Sauter D, Newman T, et al. Continuous versus intermittent albuterol nebulization in the treatment of acute asthma. Ann Emerg Med 1993;22:1847-53.

127. Rossing TH, Fanta CH, McFadden ER Jr. The effect of outpatient treatment of asthma with beta-agonists on the response to sympathomimetics in the emergency room. Am J Med 1983;75:781-4.

128. Salmeron S, Brochard L, Mal H, et al. Nebulized versus intravenous albuterol in hypercapnic acute asthma. A multicenter, double-blind, randomized study. Am J Respir Crit Care Med 1994;149:1466-70.

129. Lawford P, Jones B, Milledge J. Comparison of intravenous and nebulised salbutamol in initial treatment of severe asthma. BMJ 1978;1:84-5.

130. Swedish Society of Chest Medicine. High-dose inhaled versus intravenous salbutamol combined with theophylline in severe acute asthma. Eur Respir J 1990;3:163-70.

131. Travers AH, Rowe BH, Barker S, et al. The effectiveness of IV beta-agonists in treating patients with acute asthma in the emergency department. A meta-analysis. Chest 2002;122:1200-7.

132. Putland M, Kerr D, Kelly AM. Adverse events associated with the use of intravenous epinephrine in emergency department patients presenting with severe asthma. Ann Emerg Med 2006;47:599-63.

133. Appel D, Karpel J, Sherman M. Epinephrine improves expiratory flow rates in patients with asthma who do not respond to inhaled metaproterenol sulfate. J Allergy Clin Immunol 1989;84:90-8.

134. Turner MO, Patel A, Ginsberg S, et al. Bronchodilator delivery in acute airflow obstruction: a meta-analysis. Arch Intern Med 1997;158:1736-44.

135. Cates CJ, Crilly JA, Rowe BH. Holding chambers (spacers) versus nebulisers for beta-agonist treatment of acute asthma. Cochrane Database Syst Rev 2006;(2) CD000052.

136. Idris AH, McDermott MF, Raucci JC, et al. Emergency department treatment of severe asthma. Metered-dose inhaler plus holding chamber is equivalent in effectiveness to nebulizer. Chest 1993;103:665-72.

137. Camargo CA Jr, Spooner $\mathrm{CH}$, Rowe $\mathrm{BH}$. Continuous versus intermittent beta-agonists in the treatment for acute asthma. Cochrane Database Syst Rev 2003;(4) CD001115

138. Rodrigo GJ, Rodrigo C. Continuous vs intermittent beta-agonists in the treatment of acute adult asthma: a systematic review with meta-analysis. Chest 2002;122:160-5.

139. Rodrigo GJ, Castro-Rodriguez JA. Anticholinergics in the treatment of children and adults with acute asthma: a systematic review with meta-analysis. Thorax 2005;60:740-6.

140. Rodrigo GJ, Rodrigo C. First-line therapy for adult patients with acute asthma receiving a multiple-dose protocol of ipratropium bromide plus albuterol in the emergency department. Am J Respir Crit Care Med 2000;161:1862-8.

141. Rowe BH, Spooner C, Ducharme FM, et al. Early emergency department treat ment of acute asthma with systemic corticosteroids. Cochrane Database Syst Rev 2001;(1):CD002178

142. Rowe BH, Keller JL, Oxman AD. Effectiveness of steroid therapy in acute exacerbations of asthma: a meta-analysis. Am J Emerg Med 1992;10:301-10.

143. Harrison BD, Stokes TC, Hart GJ, et al. Need for intravenous hydrocortisone in addition to oral prednisolone in patients admitted to hospital with severe asthma without ventilatory failure. Lancet 1986;1:181-4.

144. Manser R, Reid D, Abramson MJ. Corticosteroids for acute severe asthma in hospitalised patients. Cochrane Database Syst Rev 2001;(1):CD001740.

145. McFadden ER Jr. Dosages of corticosteroids in asthma. Am Rev Respir Dis 1993 147:1306-10.

146. Rodrigo GJ. Comparison of inhaled fluticasone with intravenous hydrocortisone in the treatment of adult acute asthma. Am J Respir Crit Care Med 2005;171:1231-6.

147. Rodrigo G. Rapid effects of inhaled corticosteroids in acute asthma. An evidence based evaluation. Chest 2006;130:1301-11.

148. Rodrigo G, Rodrigo C. Inhaled flunisolide for acute severe asthma. Am J Respir Crit Care Med 1998;157:698-703.
149. Edmonds M, Camargo CA Jr, Pollack CV Jr, et al. Early use of inhaled corticosteroids in the emergency department treatment of acute asthma. Cochrane Data base Syst Rev 2003;(3):CD002308.

150. Edmonds ML, Camargo CA Jr, Pollack CV Jr, et al. The effectiveness of inhaled corticosteroids in the emergency department treatment of acute asthma: a metaanalysis. Ann Emerg Med 2002;40:145-54.

151. Rowe BH, Bretzlaff J, Bourdon C, et al. Magnesium sulfate for treating exacerbations of acute asthma in the emergency department. Cochrane Database Syst Rev 2000;(4):CD001490

152. Blitz M, Blitz S, Hughes R, et al. Aerosolized magnesium sulfate for acute asthma: a systematic review. Chest 2005;128:337-44.

153. Parameswaran K, Belda J, Rowe BH. Addition of intravenous aminophylline to beta2-agonists in adults with acute asthma. Cochrane Database Syst Rev 2000;(4) CD002742.

154. Rodrigo C, Rodrigo G. Treatment of acute asthma: lack of therapeutic benefit and increase of the toxicity from aminophylline given in addition to high doses of salbutamol delivered by metered-dose inhaler with a spacer. Chest 1994;106:1071-6.

155. Rodrigo GJ, Rodrigo C, Pollack CV, et al. Use of helium-oxygen mixtures in the treatment of acute asthma: a systematic review. Chest 2003;123:891-6.

156. Ho AM, Lee A, Karmakar MK, et al. Heliox vs air-oxygen mixtures for the treatment of patients with acute asthma: a systematic overview. Chest 2003;123:882-90.

157. Murphy VE, Clifton VL, Gibson PG. Asthma exacerbations during pregnancy: incidence and association with adverse pregnancy outcomes. Thorax 2006;61:169-76.

158. Cydulka RK, Emerman CL, Schreiber D, et al. Acute asthma among pregnant women presenting to the emergency department. Am J Respir Crit Care Med 1999; 160:887-92.

159. Grunfeld AF, FitzGerald JM. Discharge considerations for adult asthmatic patients treated in emergency departments. Can Respir J 1996;3:322-4.

160. Emerman CL, Woodruff PG, Cydulka RK, et al. Prospective multicentre study of relapse following treatment for acute asthma among adults presenting to the emergency department. MARC Investigators. Multicenter Asthma Research Collaboration. Chest 1999;115:919-27.

161. Banner AS, Shah RS, Addington WW, et al. Rapid prediction of need for hospitalization in acute asthma. JAMA 1976;235:1337-8.

152. Nowak RM, Pensler MI, Sakar DD, et al. Comparison of peak expiratory and FEV admission criteria for acute bronchial asthma. Ann Emerg Med 1982;11:64-9.

163. Corre KA, Rothstein RJ. Assessing severity of adult asthma and need for hospitalization. Ann Emerg Med 1985;14:45-52.

164. Rowe BH, Spooner CH, Ducharme FM, et al. Corticosteroids for preventing relapse following acute exacerbations of asthma. Cochrane Database Syst Rev 2007;(3):CD000195

165. Chapman KR, Verbeek PR, White JG, et al. The effect of a short course of prednisone in the prevention of early relapse after the emergency room treatment of acute asthma. N Engl J Med 1991;324:788-94

166. O'Driscoll BR, Kalra S, Wilson M, et al. Double-blind trial of steroid tapering in acute asthma. Lancet 1993;341:324-7.

167. Rowe BH, Bota GW, Fabris L, et al. Inhaled budesonide in addition to oral corticosteroids to prevent asthma relapse following discharge from the emergency department: a randomized controlled trial. JAMA 1999;281:2119-26.

168. Edmonds ML, Camargo CA Jr, Brenner BE, et al. Replacement of oral corticosteroids with inhaled corticosteroids in the treatment of acute asthma following emergency department discharge: a meta-analysis. Chest 2002;121:1798-805.

169. FitzGerald JM, Shragge D, Haddon J, et al. A randomized, controlled trial of high dose, inhaled budesonide versus oral prednisone in patients discharged from the emergency department following an acute asthma exacerbation. Can Respir J 2000;7:61-7.

170. Rowe BH, Wong E, Blitz S, et al. Adding long-acting beta-agonists to inhaled corticosteroids after discharge from the emergency department for acute asthma: a randomized controlled trial. Acad Emerg Med 2007;14:833-40.

171. Ducharme F, Di Salvio F. Anti-leukotriene agents compared to inhaled corticosteroids in the management of recurrent and/or chronic asthma in adults and children. Cochrane Database Syst Rev 2003;(4):CD002314.

172. Krishnan JA, Riekert KA, McCoy JV, et al. Corticosteroid use after hospital discharge among high-risk adults with asthma. Am J Respir Crit Care Med 2004;170:1281-5.

173. Saunders CE. Patient compliance in filling prescriptions after discharge from the emergency department. Am J Emerg Med 1987;5:283-6.

174. Thomas EJ, Burstin HR, O'Neil AC, et al. Patient non-compliance with medical advice after the emergency department visit. Ann Emerg Med 1996;27:49-55.

175. Hodder R. The paradox of adult asthma control: "Who's in control anyway?" Can Respir J 2007;14:229-34.

176. Smith A, Krishnan J, Bilderback A, et al. Depressive symptoms and adherence to asthma therapy after hospital discharge. Chest 2006;130:1034-8.

177. Chan JS, Cowie RL, Lazarenko GC, et al. Comparison of intramuscular betamethasone and oral prednisone in the prevention of relapse of acute asthma. Can Respir J 2001;8:147-52.

178. McNamara RM, Rubin JM. Intramuscular methylprednisolone acetate for prevention of relapse in acute asthma. Ann Emerg Med 1993;22:1829-35.

179. Schuckman H, DeJulius D, Blanda M, et al. Comparison of intramuscular triamcinolone and oral prednisone in the outpatient treatment of acute asthma: a randomized controlled trial. Ann Emerg Med 1998;31:333-8.

180. Gibson PG, Powell H. Written action plans for asthma: an evidence-based review of the key components. Thorax 2004;59:94-9.

181. Gibson PG, Powell H, Coughlan J, et al. Self-management education and regula practitioner review for adults with asthma. Cochrane Database Syst Rev 2003;(1):CD001117.

182. Coté J, Bowie D, Robichaud P, et al. Evaluation of two different educational inter- 
ventions for adult patients consulting with an acute asthma exacerbation. Am J Respir Crit Care Med 2001;163:1415-9.

183. Cowie RL, Revitt SG, Underwood MF, et al. The effect of a peak flow-based action plan in the prevention of exacerbations of asthma. Chest 1997:112:1534-8.

184. Powell H, Gibson P. Options for self-management education for adults with asthma. Cochrane Database Syst Rev 2003;(1):CD004107.

185. Balter MS, Bell AD, Kaplan AG, et al. Management of asthma in adults. CMAJ 2009. DOI:10.1503/cmaj.080007.

186. Rydman RJ, Isola ML, Roberts RR, et al. Emergency department observation unit versus hospital inpatient care for a chronic asthmatic population: a randomized trial of health status outcome and cost. Med Care 1998;36:599-609.

187. Osman LM, Calder C, Godden DJ, et al. A randomised trial of self-management planning for adult patients admitted to hospital with acute asthma. Thorax 2002; 57:869-74.

188. Nair P, Hargreave F. Airway diseases, inflammometry and individualized therapy. In: Polosa R, Holgate ST, editors. Therapeutic strategies in asthma: current treatments. Oxford (UK): Clinical Publishing, 2007. p. 155-64.

189. Camargo CA Jr, Smithline HA, Malice MP, et al. A randomized controlled trial of intravenous montelukast in acute asthma. Am J Respir Crit Care Med 2003;167: 528-33.

190. Spears M, Donnelly I, Jolly L, et al. Effect of low-dose theophylline plus beclomethasone on lung function in smokers with asthma: a pilot study. Eur Respir J 2009;33:1010-7.

191. Fan Chung K. Phosphodiesterase inhibitors in airways disease. Eur J Pharmacol 2006;533:110-7.

Correspondence to: Dr. Rick Hodder, Divisions of Pulmonary and Critical Care Medicine, The Ottawa Hospital - Civic Campus, Ottawa ON K1Y4E9; rhodder@ottawahospital.on.ca
This article is the fifth in a seven-part case study series that was developed as a knowledge translation initiative of the Canadian Thoracic Society Asthma Committee. The series aims to educate and inform primary care providers and nonrespiratory specialists about the diagnosis and management of asthma. The key messages presented in the cases are not clinical practice guidelines but are based on a review of the most recent scientific evidence available. Financial support for the publication of this series has been provided, in part, by the Canadian Thoracic Society.

\section{Articles to date in this series}

- Subbarao P, Mandhane PJ, Sears MR. Asthma: epidemiology, etiology and risk factors. CMAJ 2009. DOI:10.1503/cmaj.080612.

- Kaplan AG, Balter MS, Bell AD, et al. Diagnosis of asthma in adults. CMAJ 2009. DOI:10.1503/cmaj.080006.

- Balter MS, Bell AD, Kaplan AG, et al. Management of asthma in adults. CMAJ 2009. DOI:10.1503/cmaj.080007.

- Chapman KR, Mclvor RA. Asthma unresponsive to usual care. CMAJ 2009. DOI:10.1503/cmaj.090089. 